\title{
PUNTUALIZACIONES SOBRE UN GOLPE DE ESTADO
}

\author{
JUAN VELARDE FUERTES \\ Universidad Complutense
}

El mundo histórico de la Dictadura, iniciado con el golpe de Estado de 13 de septiembre de 1923, tuvo un primer tratamiento apresurado. Se trata del desatado a partir de su caída, en 1930, con el prólogo de lo escrito por los opositores a Primo de Rivera en plena vigencia del proceso dictatorial. No conviene despreciar estos materiales. Pero, lo mismo que acontece con los hagiográficos que abundaron de septiembre de 1923 a enero de 1930, han de someterse a juicios críticos muy fuertes. Todos los que han trabajado el periodo - si han querido ser solventes- los han utilizado tras rectificarlos a fondo.

Hasta bastante después de nuestra guerra civil vino una gran pausa. $\mathrm{Pa}$ reció como si los historiadores se hubiesen puesto de acuerdo en la necesidad de dar un poco de tiempo al tiempo, para observar las cosas con mayor serenidad.

Así es como se ha iniciado una importante labor de rectificación -y si se me apura-, de reelaboración histórica del período, a la que algunos hemos contribuido desde variados ángulos. Ahí es donde, en principio, debe inscribirse el reciente libro de Javier Tusell, Radiografía de un golpe de Estado. El ascenso al poder del general Primo de Rivera!

Dos cosas conviene decir de modo inmediato. La primera, que es una obra que trata de cohonestar la investigación histórica con el interés del lector Esto, en principio, no es ninguna cosa mala si logran mantenerse ambas cosas, esto es, el rigor y la amenidad. Sin necesidad de recurrir al socorrido Le Roy Ladurie, basta mencionar esa maravilla de relato de la batalla de Coviadonga que debemos a don Claudio Sánchez-Albornoz. ¿Para qué seguir con más ejemplos?

La segunda cuestión previa es que se trata de un libro que procura dirigirse en derechura a la aclaración de zonas que estaban muy oscuras. También esto es, en principio, el papel básico de un historiador. Ahora mismo presenciamos una especie de prodigiosa concatenación de indagaciones sobre nuestra

\footnotetext{
'Alianza Editorial, Madrid, 1987, 294 pp.
} 
historia económica contemporánea. Afortunadamente para la ciencia, no dan paz a sus manos y, por ello, mil oscuridades de los siglos $\mathrm{xIX}$ y $\mathbf{X X}$ comienzan a disolverse. La investigación de Tusell trata de penetrar en una región particularmente confusa siempre: las interioridades previas al inicio de un golpe de Estado. En el caso concreto del capitaneado por Miguel Primo de Rivera, arrastró los flecos polémicos del papel en el mismo, en sus antecedentes, en su consolidación, de Alfonso XIII; también se habló mucho de la conexión del golpe con el asunto de las responsabilidades y, por eso, con el expediente Picasso.

Cuando una obra aborda cuestiones así de peliagudas, conviene someterla a toda clase de contrastes. Si los pasa con éxito, es muy probable que gran parte de lo que en ella se ofrece sea oro, y no oropel engañoso. Cabe la posibilidad de que el autor ofrezca una amalgama de oro y oropel. Denunciado éste, corresponde a quien cometió esa ligereza probar de modo fehaciente que el resto es metal valiosísimo y no bajo. El silencio, incluso respecto a aquello no denunciado, significaría una peligrosa admisión de ligereza. El estricto mundo de la ciencia, que se solaza cuando se unen investigación y galanura, como he dicho, lleva muy a mal que se le intente meter gato por liebre. Tolera un trabajo incipiente, incompleto, porque en mayor o menor grado todos lo son. No brillos de abalorios que se pretenden diamantinos.

Dicho todo esto, he de señalar que sometí la obra de Tusell al contraste de lo que es de corriente conocimiento entre los economistas españoles. Inmediatamente se detectaron cuatro cuestiones que deben ponerse de relieve. ¿Son las únicas? Después seguiré con el asunto, pero he de empezar por ellas.

\section{La cuestión Alba}

Uno de los datos esenciales del alzamiento del 13 de septiembre de 1923 es haber escogido a Santiago Alba como chivo expiatorio. ¿Por qué esa animadversión hacia este político? Tusell ofrece ciertas informaciones de tipo militar; también alusiones a otros aspectos de su vida, no sé, ni de lejos ni, por cierto, me importa, si ciertos o calumniosos, que parece pretenden mostrar una especie de rechazo muy amplio a la persona de este político. Dentro de este tipo de historia, aquí se llega incluso a un lenguaje a lo Mingo Revulgo en las coplas recogidas en la página 51 . A mí esto, en principio, me disgusta, salvo cuando se me prueba que es ineludible una excursión a lo que más de una vez he calificado de bistoria chacal, porque sin ello no se entiende alguna cuestión clave.

El lector creerá que ahí puede quedar todo. Sin embargo, no es así. Una consulta a trabajos de economistas e historiadores mostraría otra cosa. En 
primer lugar, éstos destacan la polémica Alba-Cambó en relación con el proyecto de ley de impuesto sobre los beneficios extraordinarios conseguidos en la IGM. Desde Jesús Pabón a las minuciosas investigaciones de los profesores Roldán, García Delgado y Juan Muñoz, sabemos que la polémica no sólo fue durísima, sino que sirvió para que Cambó alzase a la periferia industrial -la catalana textil, la siderometalúrgica vasca y la carbonera asturiana- contra lo que se hizo ver como una especie de ínfula castellanizante de Alba. A través del marqués de Comillas, Cambó procuró incluso influir sobre la Corona. El estudio de las consecuencias de esta violenta discusión se amplía de día en día. Muy recientemente, por ejemplo, se nos ha aclarado por Gabriel Tortella y Juan Carlos Jiménez, en su Historia del $B C I^{2}$, de qué modo el armisticio -que no paz- con que se concluyó aquel choque puso en marcha al Banco de Crédito Industrial.

Pero hay más. Alba, en el gobierno de García Prieto, era ministro de Estado. Más de una vez en ese mismo gobierno -que, no se olvide, era un Gabinete de conjunción liberal- se habian criticado las actitudes proteccionistas. Un año antes, en 1922, como saben bien economistas e historiadores, el proceso del proteccionismo integral y del nacionalismo económico había culminado con el Arancel Cambó. Inmediatamente se inició una fuerte ofensiva internacional contra él, que habría de culminar con el famoso estudio del formidable nivel de la protección española presentado por la Sociedad de las $\mathrm{Na}$ ciones, que provocó, por ejemplo, una violenta reacción por parte de Pedro Gual Villalbí. El mundo empresarial catalán, golpeado por la crisis económica y por el pistolerismo desatado en las calles de Barcelona, temía que a todo esto se añadiese algún asalto, desde el poder, al Arancel Cambó. Conviene recordar que, a partir del Arancel de 1877, todos —esto es, los Aranceles de $1882,1891,1906$ y 1922 - contienen dos columnas. El tema de la segunda columna motiva un entrelazamiento, que los contemporáneos conocen muy bien, entre política proteccionista y tratados comerciales. ¿Puede nadie ignorar que el famoso Memorial de Greuges ${ }^{3}$ se debió al modus vivendi con Inglaterra aprobado en 1885? ¿Qué bullía en 1923 en la cabeza de Santiago Alba? ¿Hasta dónde estaba dispuesto a llegar? Añádase que en Hacienda, en ese gobierno, estaba Pedregal, que jamás había ocultado sus convicciones librecambistas.

Por ahí, esto es, en los viejos archivos del Ministerio de Estado, y no en coplas, es por donde se puede encontrar la raíz de una maniobra en la que,

2 Banco de Crédito Industrial, Madrid, 1986.

- El título exacto es Memoria en defensa dels interessos morals $i$ materials de Catalunya, Estampa de Lluis Tasso, Barcelona, 1885; bien conocida es su vinculación con la consolidación del catalanismo. 
a mi juicio, cayó ingenuamente Miguel Primo de Rivera. El fracaso judicial en relación con este asunto lo prueba con largueza.

\section{La cuestión Puig i Cadafalch}

Una buena investigación sobre las relaciones entre Puig i Cadafalch y Primo de Rivera en Barcelona hubiese ya aportado alguna claridad casi de modo seguro a la cuestión anterior. Pero sobre el acercamiento entre ambos se investiga con escaso cuidado en este libro de Tusell.

Una prueba señera se encuentra en el relato de la despedida de Primo de Rivera en la estación de Francia, el 14 de septiembre de 1923, por parte de una serie de personalidades barcelonesas. ¿A quién destaca el autor en esa despedida? Por un lado, al marqués de Alella, alcalde de la ciudad; por otro, al obispo, que «le bendijo». Sin embargo, alli estaba Puig i Cadafalch, que le abrazó. En la obra ni se relata la presencia ni el abrazo.

Sin embargo, ambas cosas eran mucho más importantes que la presencia $\mathrm{y}$ anécdotas de alcalde y obispo. Fijémonos, en cambio, cómo destaca el hecho, entre otros muchos, Cambó en sus Memorias (1876-1936) 4 .

El recalcar esto es lógico. Josep Puig i Cadafalch, un prestigioso arquitecto de Barcelona, es el sucesor de Enric Prat de la Riba, a partir de la muerte de éste y hasta la llegada de la Dictadura, en el puesto de presidente de la Mancomunidad de Cataluña. Además, era persona muy ligada, por una parte, a la Lliga; por otra, era de modo clarísimo una especie de portavoz del Fomento del Trabajo Nacional. Como su antecesor en la Mancomunidad, se había convertido en una especie de hombre-bisagra de enorme importancia entre el catalanismo y el movimiento proteccionista.

En aquellos momentos el mundo industrial catalán tenía la sensibilidad en carne viva. No era sólo la cuestión arancelaria y de los tratados de comercio de que he hablado antes; tampoco era sólo el pistolerismo; se defendía la economía catalana, en su proyección burguesa, de pérdida de identidad, a causa de lo que había significado la suspensión de pagos —en realidad, una quiebra- del Banco de Barcelona, sucedida bien poco antes y a la que no se dedica en este libro ni una línea. Estaban en juego el fuero y el huevo de la región. Se contemplaba como máximo defensor de ambos a Puig i Cadafalch, que trataba de hacerse digno de la presidencia del organismo preautonómico que Prat de la Riba había puesto en marcha.

De algún modo, el abrazo en la estación de Francia era una especie de signo externo de una alianza muy significativa, y como tal la consideraron

\footnotetext{
- Alianza Editorial, Madrid, 1987, p. 366.
} 
todos. Sabido es que la cosa quedó en nada. Sin embargo, el papel como arquitecto de Puig i Cadafalch en esa gran apoteosis de la Dictadura que fue la Exposición Universal de Barcelona en 1929, parece probar que sus relaciones personales con el dictador debían ser buenas.

\section{La cuestión Flores de Lemus}

Si todo lo anterior parece obligar a reescribir, o a considerar de otro modo, el enlace del mundo catalán con Primo de Rivera, lo acontecido con Flores de Lemus es posible que exija repasar de otro modo toda la cuestión del gobierno tecnocrático transmutado en directorio militar.

Escribe Tusell que los conspiradores, que había pasado a encabezar Miguel Primo de Rivera, parecía que no deseaban el poder. Lo que pensaban era derrocar la estructura política de gobierno de la Restauración. Imaginaban sustituirla por una especie de gobierno de notables, de despotismo ilustrado, de gobierno tecnocrático. Según la versión del general Saro ante la Comisión de Responsabilidades, Primo de Rivera sólo había pensado en ser jefe del Estado Mayor Central. De modo simultáneo se constituiría un gobierno de liquidación de los políticos profesionales. Este Gabinete se compondría de «elementos intelectuales hasta ese día apartados de... [las Cortes] y de los partidos y organizaciones políticas actuantes». Tanto Saro como Federico Berenguer mencionan como nombres que barajaban para ese gobierno de saneamiento los de Torres Quevedo, Marañón, Ramón y Cajal, Maeztu, Llaneza, Unamuno y Flores de Lemus. Federico Berenguer habla de gestiones con Maeztu y Llaneza. El trato de éste con el general Primo de Rivera fue siempre cordial. Se reunieron más de una vez a almorzar en Casa Mingo, un restaurante asturiano situado en la calle de Echegaray. A Maeztu se le designaría embajador en Buenos Aires.

Mas he aquí que Tusell, en la página 246, indica que Primo de Rivera «durante el viaje a Madrid», en la noche del 14 al 15 de septiembre de 1923 , decide abandonar la idea. Las consecuencias de esto no se le podían escapar al alzado. Un Gabinete civil podía presentarse ante las Cortes, con lo que se salvaría la continuidad política, sin excesivos traumas, aunque se abriese incluso un período constituyente. Sería algo parecido a lo que sucedió, también tras una conmoción militar - no se olvide-, con el paso de la IV a la V República encabezada por el general De Gaulle. El rey estaba también muy interesado en la continuidad. Incluso envía un vehículo de Palacio al ministro de Gracia y Justicia dimisionario, que estaba enfermo, para que así éste pudiese recibir el juramento de Primo de Rivera como presidente del Consejo de Ministros. 
Esta especie de corazonada ferroviaria nocturna no es verosímil, en absoluto. Los economistas algo sabemos de esto. En vida de Antonio Flores de Lemus, José G. Ceballos Teresí imprimió por vez primera el relato, y nadie lo rectificó entonces, ni, por supuesto, el propio Flores. En multitud de ocasiones se ha recogido con esta fuente. Según el mencionado testimonio de Ceballos, que en estas cosas siempre está bien documentado, al llegar a Madrid Primo de Rivera traía en su cartera como miembro de su Gabinete, en el puesto de ministro de Hacienda, a Flores de Lemus. Este lo declinó ante el dictador. Le argumentó que tras un golpe militar no podían gobernar los civiles, sino quienes se habían pronunciado. El emparentamiento de esto con la opinión de Antonio Maura y la cordialísima relación que siempre existió entre Flores de Lemus y éste parece interesante. Pero lo que resulta fuera de duda es que Flores dijo que no.

Si es así, ¿cuándo lo supo Primo de Rivera? ¿Manifestaron el resto su negativa el 13 o el 14? ¿Fue al llegar a Madrid Primo de Rivera?

El relato del cambio súbito que hace Tusell no es verosímil. Más bien parece una obligada asunción de responsabilidades. En esta obra poco se habla de lo ocurrido entre el momento de la llegada de Primo a Madrid - nueve treinta de la mañana- y la una de la tarde, en que comunica, primero al general Muñoz Cobos y después a los periodistas, que juraría ante el ministro de Gracia y Justicia dimisionario como presidente del Consejo de Ministros, pero que formaría «un Directorio militar compuesto de generales de brigada, los más modernos». ¿Fue entonces cuando Flores de Lemus y, directa o indirectamente, los otros miembros de ese gobierno le dijeron que no aceptaban las carteras? ¿O lo había sabido ya en Barcelona total o parcialmente?

Tusell todo esto lo investiga mal. Con decir que no ha consultado siquiera los ejemplares de la Gaceta de Madrid de esos días - fuente que en situaciones de ruptura histórica ilumina mucho las cosas- basta y sobra. Para los economistas, sin embargo, era conocido ese cambio por negativa del interesado en Hacienda. Lo que es más lógico va por ahí, y debemos abandonar la corazonada del coche-cama.

\section{La cuestión Suárez Inclán}

En el gobierno García Prieto, muy a última hora de su existencia y dentro de las consecuencias de la reorganización planteada por la crisis del 1 al 3 de septiembre de 1923, Félix Suárez Inclán sustituyó en la cartera de $\mathrm{Ha}$ cienda a Miguel Villanueva, al que, por cierto, en la página 282 se confunde 
con Francisco Villanueva, el periodista autor de Obstáculos tradicionales. Crónica de los bechos determinantes del golpe de Estado en $1923^{3}$.

Dejemos eso a un lado, de momento. ¿Quién era Félix Suárez Inclán? Hijo del político avilesino Estanislao Suárez Inclán, había estudiado en la Universidad Central las carreras de Filosofía y Letras y Derecho. Había conseguido el número uno en la oposición a registradores de la propiedad. Tuvo siempre un gran prestigio como abogado. Los Suárez Inclán eran una familia política liberal asturiana. Félix Suárez Inclán ya había sido ministro dos veces, una de Hacienda. Resultó desde entonces muy conocido de los historiadores de nuestra Hacienda por su proyecto de impuesto sobre la renta, en el que también participó Flores de Lemus. Después fue presidente del Consejo Superior Bancario, teniendo de secretario al conocido economista Francisco Bernis. En la historia financiera española procede de él la organización eficaz de las Cámaras de Compensación bancaria. Se trata, pues, de alguien definidísimo para todos los economistas, y sobre todo si son historiadores de nuestra economía.

¿Por qué se le nombra sucesor en medio de todo el combate posterior a Pedregal, entre Villanueva y Chapaprieta? A mi juicio, en lo que he investigado sobre este gobierno, por tres motivos. Había sido, en un momento muy peligroso del pistolerismo callejero, gobernador civil de Barcelona. Había demostrado en el puesto ser hombre de temple y había mantenido excelentes relaciones con el mundo empresarial catalán. Por suscripción, los patronos catalanes le habían regalado las insignias de la Gran Cruz de Isabel la Católica que, al cesar, le había concedido el gobierno. Tenía también buenas relaciones con Francia. Por eso, el gobierno de la III República le había distinguido con las insignias de Gran Oficial de la Legión de Honor. Las buenas relaciones con Francia eran muy importantes entonces, tanto por lo que se refería a los acuerdos comerciales como al cada vez más sangriento conflicto de Marruecos. Aparte de esto tenía prestigio como hacendista y experiencia en el puesto.

Antes de seguir adelante es preciso señalar la existencia de otra rama de los Suárez Inclán. Se trata de la encabezada por el prestigiosísimo militar, que llegó a las mayores cumbres de la milicia, Julián Suárez Inclán. A ella pertenecen otros militares muy conocidos, entre los que destaca, precisamente, quien, en 1923, había llegado al generalato. Es obvio que en la historia de España tienen marcadísima personalidad los Suárez Inclán políticos, liberales y brillantes juristas; gente de toga, en suma. También la tienen los Suárez Inclán militares, de escalas cerradas, de Estado Mayor, con un papel grande en la Real Sociedad Geográfica, amigos del prestigioso general Gómez de Arteche. Estos militares no eran precisamente proclives a asonadas o pronuncia-

s Madrid, 1927. 
mientos. Pues bien, en este libro de Tusell, en la página 184, se puede leer: «Uno de los ministros, el de Hacienda, Suárez Inclán, que había entrado recientísimamente en el Gobierno, hubo de ser requerido en su propia casa por el segundo jefe de la Dirección General de Seguridad; era general de división y, según testimonio del presidente del Gobierno, el único militar en cuya lealtad pudo confiar el Gobierno de Madrid.» En la página 189 reincide: «Como sabemos, el ministro de Hacienda era general de división en la guarnición en Madrid y, por tanto, persona muy apropiada para tratar de sondear a la oficialidad de la capital. Lo hizo y trajo pésimas noticias para el Gobierno.»

¿Para qué insistir más en la vasta confusión que, de modo asombroso, porque todos son personajes eminentes de la historia contemporánea de España, existe en esta obra con la familia Suárez Inclán?

\section{La raíz de estas confusiones}

La raíz de estas confusiones en temas archiconocidos es, a mi juicio, el apresuramiento. El profesor Tusell logró unos datos sobre el 13 de septiembre y cayó en una trampa: creer que en el duro mundo de la ciencia la rapidez en la exposición de algo que se conoce tiene algún valor.

Esta celeridad en presentar lo que obtuvo a través de Miguel Primo de Rivera y Urquijo, y alguna cosa más de menor importancia, y de hacerlo sin la humildad que siempre viene bien en estos adustos campos, se muestra en el caótico Indice onomástico, donde no ya es vano buscar a Flores de Lemus, de quien se habla dos veces, o donde se mezclan, como he dicho, los Villanueva, sino que en él no hay referencias a Miguel Primo de Rivera, marqués de Estella; pero al consultar más de una de su tío Fernando, resulta que es del sobrino.

Esto, que es desidia científica, se acentúa en la redacción. En la página 84 se lee: «En efecto, la conspiración militar que realmente estalló fue muy diferente, al menos en su apariencia externa, pero también en sus resultados, de la que realmente estalló.» En la página 20 el lector se topa con: «Habían habido problemas graves...»; en la 100 se dice: «No habían habido tales brindis..."

Otras expresiones gramaticalmente confunden. Al ignorarse las reglas de puntuación, dos sindicalistas se convierten, para el no especialista, en tres en la página 60; en la página 64 se ignora lo que quiere decir detentar; en la página 181, cuando se refiere el autor a unas declaraciones de Alfonso XIII sobre Alba, resulta imposible saber si un pronombre «él» se refiere al monarca o al político; en la 190 el juego de un «aquél» deja perplejo, porque si se 
refiere al comandante Robles debería aparecer «éste», y si no, es que Cavalcanti se aconsejaba a sí mismo.

También se encuentran incluso sin corregir algunas faltas de ortografía: «salibazo» en la página 58; o incorrecciones tan manifiestas como la del general López Ochoa - a quien todo el mundo llamó así-, al que convierte, al menos en diez ocasiones, en López de Ochoa.

¿A cuento de qué esta excursión de detalles? Si la mezclo con los cuatro huecos referentes a Alba, Puig i Cadafalch, Flores de Lemus y Suárez Inclán me proporcionan la impresión de haber tenido acceso a una especie de libro trampa. Está lleno de informaciones; pero ¿qué es lo que en ellas vale y qué es lo que está desenfocado, mal redactado o sencillamente equivocado, precisamente en aquello en lo que soy lego?

Pocas veces se tiene entre las manos una obra tan dual; llena, por una parte, de aportaciones que pueden ser valiosísimas; por ejemplo, en un semanario -en mi artículo "España: del hambre a la hartura», aparecido en Epo$\mathrm{ca}^{6}$ - se lo reconocí paladinamente, pero carente de modo sumo de ese grado de confianza que solicita el investigador que lo va a emplear. No es admisible que se nos ofrezca la cuasi seguridad de que sabemos algo y la tremenda inseguridad de comprobar que quizá la cita que deseábamos esté equivocada. Honradamente pienso que Javier Tusell tiene que reescribir de arriba abajo este libro y reducirlo a aquello que puede aportar, sin buscar títulos estrepitosos $\mathrm{y}$, menos aún, velocidades de edición.

Quizás estos consejos le parezcan duros, desagradables. Ojalá no lo considere así. Se trata de los típicos que un veterano profesor hace a uno joven al que ve con grandes posibilidades, incluidas las de triunfar y las de estrellarse.

- El 28 de septiembre de 1987, núm. 133, p. 86. 